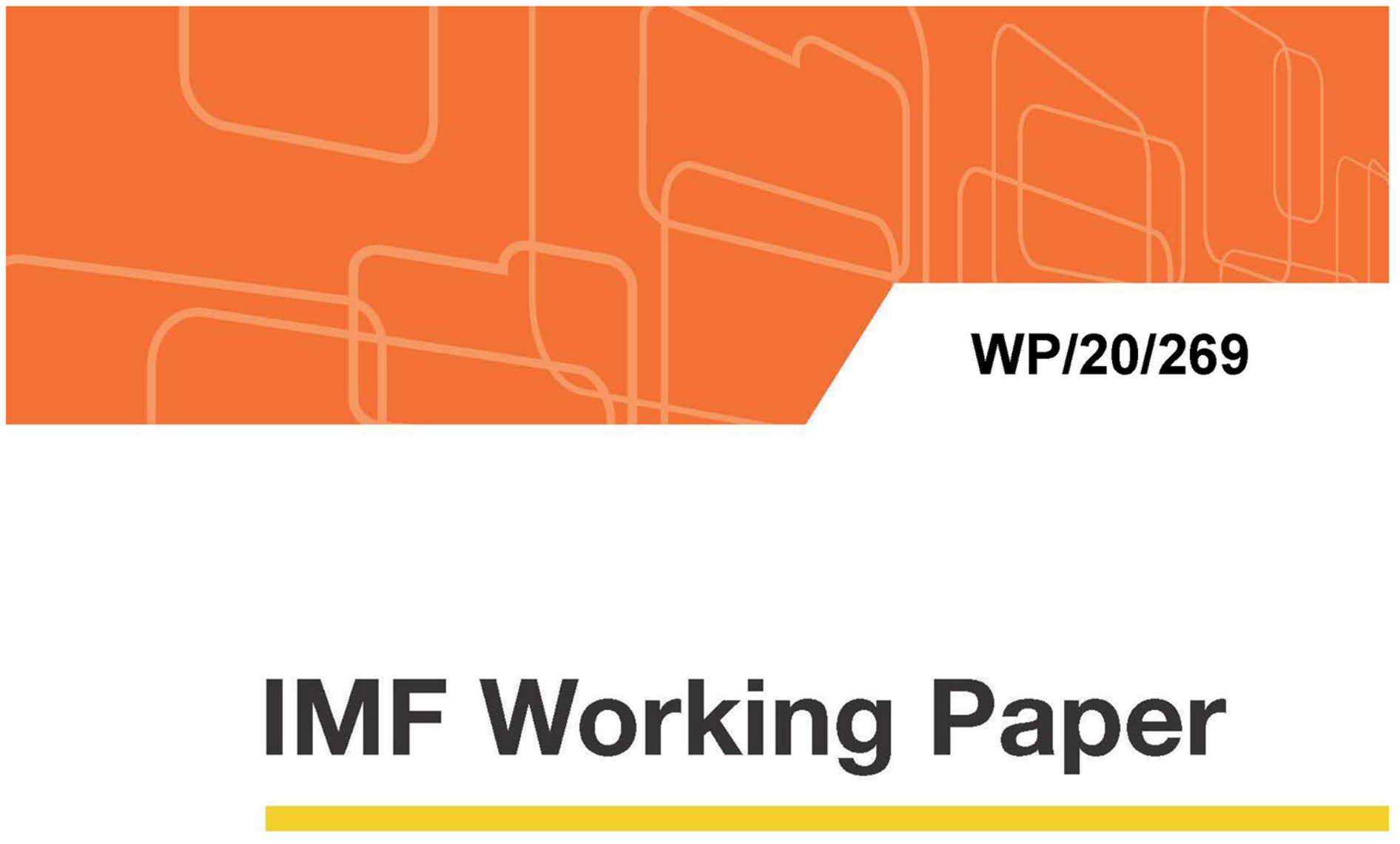

\title{
Assessing Dutch Fiscal and Debt Sustainability
}

by Benjamin Carton and Armand Fouejieu

IMF Working Papers describe research in progress by the author(s) and are published to elicit comments and to encourage debate. The views expressed in IMF Working Papers are those of the author(s) and do not necessarily represent the views of the IMF, its Executive Board, or IMF management. 


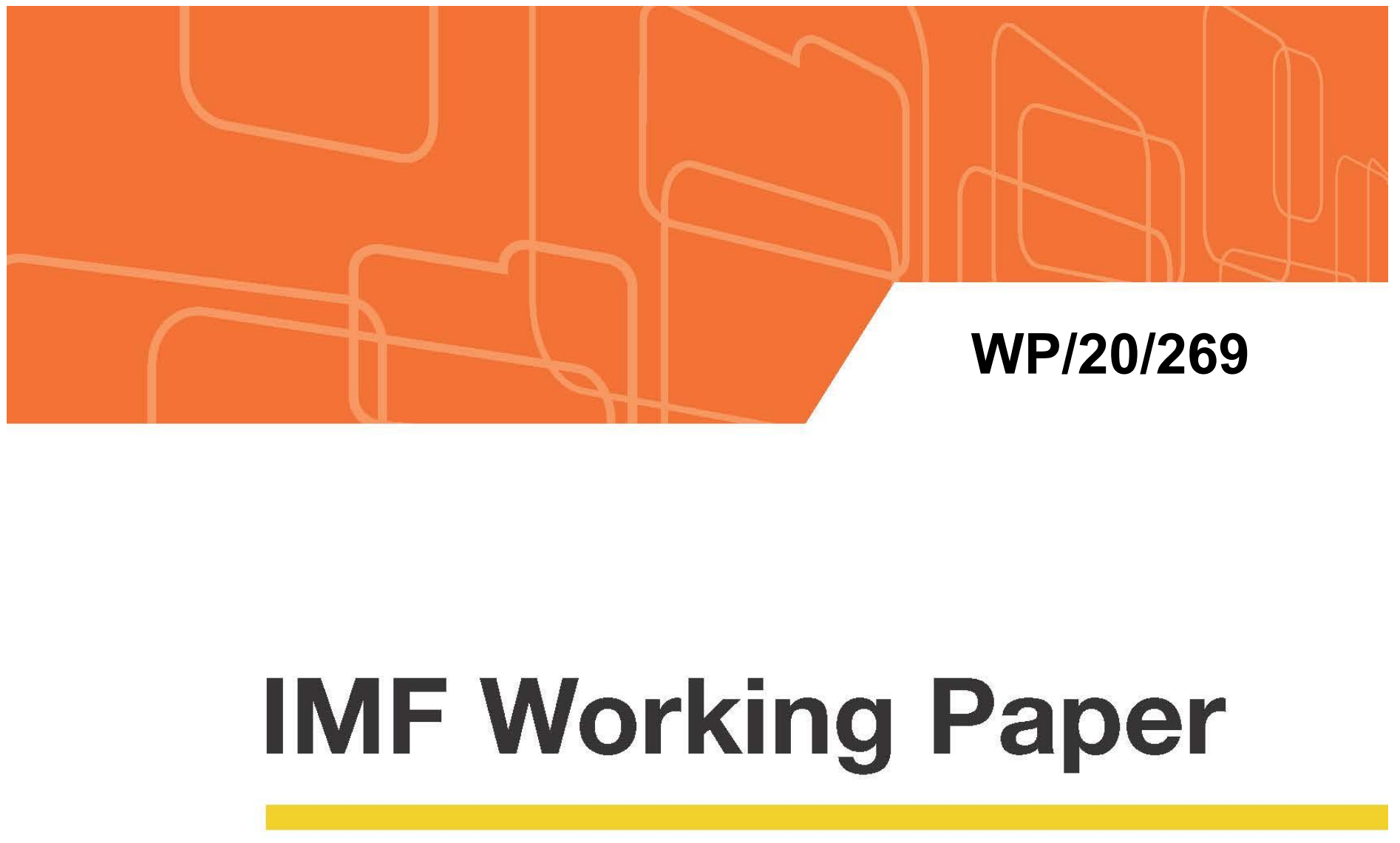

\section{Assessing Dutch Fiscal and Debt Sustainability}

by Benjamin Carton and Armand Fouejieu

IMF Working Papers describe research in progress by the author(s) and are published to elicit comments and to encourage debate. The views expressed in IMF Working Papers are those of the author(s) and do not necessarily represent the views of the IMF, its Executive Board, or IMF management. 


\title{
IMF Working Paper
}

European Department

\author{
Assessing Dutch Fiscal and Debt Sustainability \\ Prepared by Benjamin Carton and Armand Fouejieu
}

Authorized for distribution by Alfredo Cuevas

December 2020

\section{IMF Working Papers describe research in progress by the author(s) and are published to elicit comments and to encourage debate. The views expressed in IMF Working Papers are those of the author(s) and do not necessarily represent the views of the IMF, its Executive Board, or IMF management.}

\begin{abstract}
Although the Netherlands entered the so-called Great Lockdown with a strong fiscal position, the Dutch fiscal balance is projected to deteriorate by an unprecedented magnitude, largely as a result of necessary fiscal measures deployed to weather the economic impact of the COVID-19 pandemic. This paper performs a stochastic analysis of risks to Dutch fiscal and debt sustainability over the next decade, taking into account alternative recovery scenarios and associated fiscal consolidation paths and also a range of macroeconomic shocks drawn from the historical experience of the Netherlands. The simulations show that even under significant downturn scenarios and assuming an initially less favorable fiscal position due to persistent economic effects of the pandemic, risks to the Dutch fiscal and debt sustainability would remain contained.
\end{abstract}

JEL Classification Numbers: H62, H63, H68, C15

Keywords: Debt, fiscal deficit, sustainability, stochastic simulations.

Author’s E-Mail Address: bcarton@imf.org, afouejieu@imf.org 


\section{CONTENTS}

ABSTRACT _ $\underline{\underline{2}}$

I. INTRODUCTION _

II. DEBT DYNAMICS AND FISCAL POLICY BEHAVIOR___

A. Debt dynamics and interest payments ___ 6

B. Fiscal reaction function

III. THE MACRO (NON-FISCAL) FRAMEWORK ___

A. Identifying shocks to fiscal policy and public debt __ 9

B. Simulation algorithm

IV. RISKS TO DEBT AND FISCAL SUSTAINABILITY __

A. A medium-term budget balance target scenario

B. A medium-term debt objective scenario

C. A protracted fiscal consolidation scenario __ 16

V. CONCLUSION___

\section{FIGURES}

1. Prediction Power of the Fiscal Reaction Function

2. Medium-term fiscal forecasts under alternative scenarios

3 . A medium-term budget balance scenario ___

4. A medium-term debt objective scenario

5. A more protracted fiscal consolidation scenario

6. Probability distributions of debt and fiscal deficit over the forecast horizo ___

\section{APPENDICES}

1. Methodology

2. Simulated series based on the fiscal framework described in section B. ___ 23

3. Medium-term forecasts under alternative scenarios

4. Shock Simulations and Frequency Distributions 


\section{INTRODUCTION}

\section{The Dutch fiscal balance is projected to deteriorate by an unprecedented} magnitude as a result of necessary fiscal measures to weather the economic impact of the COVID-19 pandemic. As virtually all around the world, the Dutch people and economy have been significantly affected by the COVID-19 outbreak. Lockdown measures were taken starting in March 2020 to limit the spread of the virus, causing important disruptions in economic activity. The authorities have responded decisively, including to ensure that the health system can handle the increased demands posed by the disease. An important fiscal package is also being deployed to provide support to the households and businesses most affected by the outbreak. ${ }^{1}$ Furthermore, fiscal stabilizers are allowed fully to operate in a context of significant economic contraction this year. As a result, the fiscal balance is projected to deteriorate sharply in 2020. In its June update, the Dutch Ministry of Finance projects a fiscal deficit of about 8.7 percent of GDP in 2020 (from a surplus of 1.7 percent in 2019), and public debt to rise to 63 percent of GDP (from below 50 percent in 2019). ${ }^{2}$

\section{The Netherlands entered the current crisis with a strong fiscal position, which} provides room for swift policy measures to counter the shock. In the wake of the global financial crisis (GFC) and the European debt crisis, the Dutch economy grew faster than the Euro area average. However, growth softened in recent years, while potential growth flattened. Using its considerable fiscal space, fiscal accommodation supported economic activity during the GFC; this stimulus was gradually rolled back in subsequent years. This contributed to a sharp correction of the fiscal position after the GFC, with the fiscal balance posting its fourth consecutive year of surplus in 2019 ,

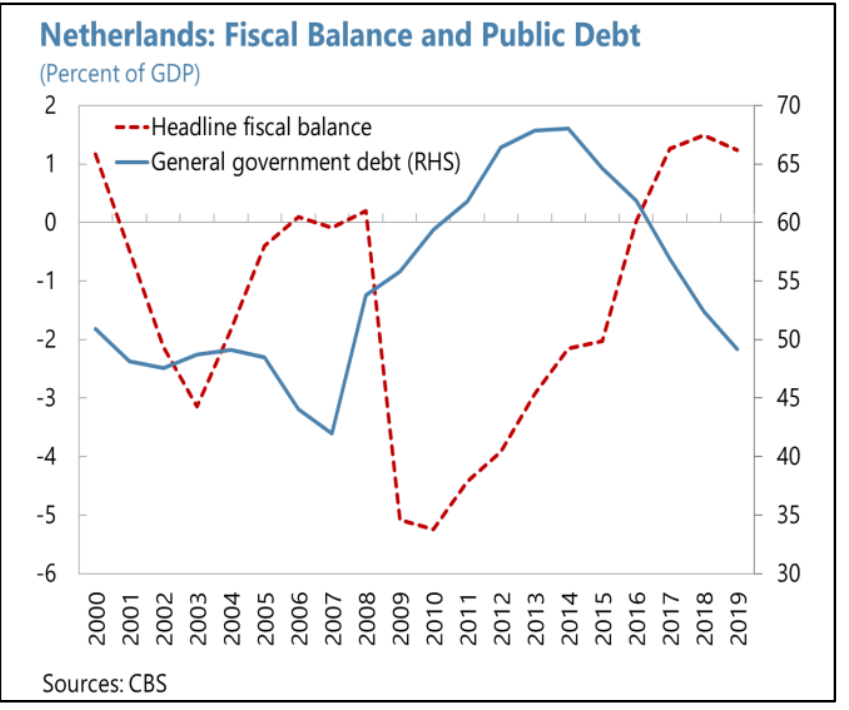
and government debt falling below 50 percent of GDP. Such fiscal policy had a dual motivation. First, the desire to rebuild buffers: a strong budget balance provides space for automatic stabilizers to fully operate, contributing to ensure strong shock absorption capacity

\footnotetext{
${ }^{1}$ Fiscal measures include for example compensations for labor costs to preserve employment, support to entrepreneurs and self-employed, allowances for SMEs to finance their fixed costs, tax payments deferral for affected companies, and guarantee schemes to ensure that businesses can continue to access financing.

2 The September 2020 forecasts of the Netherlands Bureau for Economic Policy Analysis, released after the analysis in this paper was finished, project a fiscal deficit of 7.6 percent of GDP, and public debt at 60 percent of GDP in 2020.
} 
in a severe downturn. This would be particularly important for the Netherlands given the openness of the economy and its vulnerability to global shocks. Second, more formally, fiscal policy is guided by a domestic fiscal framework that sets the main budgetary targets and modalities for potential adjustments (See Vierke and Masselink 2017 for details on the Dutch fiscal framework). Especially, by allowing key expenditure programs (e.g. unemployment and social security benefits) and tax revenues to adjust to the cycle, automatic stabilizers have performed well and the authorities have only made little use of discretionary fiscal policies in the past decades. In addition, the government takes into account long-term trends, such as population aging, when assessing the sustainability of public expenditure programs.

3. The so-called Great Lockdown and its economic and fiscal implications call for an assessment of potential risks to fiscal and debt sustainability, especially taking into account alternative recovery scenarios. A wide range of forecasts suggest that the 2020 fiscal deficit could be twice as large as the deficit that prevailed during the GFC, and Dutch government debt is projected to increase by about 15 percentage points of GDP from 2019 levels. The unprecedented size of the fiscal deficit and debt increase warrants investigating whether medium-term fiscal and debt sustainability may be at risk. The evolution of the pandemic remains largely unpredictable, adding more uncertainties to required fiscal responses. This also raises the question of how much fiscal room remains available to continue providing support to the economy without affecting fiscal sustainability. A related question concerns the medium-term fiscal adjustment path that would contribute to safeguard sound public finances while ensuring that key medium-term objectives (including supporting potential growth) remain a priority.

\section{This paper performs a stochastic analysis of risks to Dutch fiscal and debt}

sustainability. We investigate to what extent macroeconomic shocks could create deviations of public debt and fiscal balance from a sustainable trajectory in the current juncture. We do so by generating series of macroeconomic stochastic shocks to the main determinants of public debt and feed them into a fiscal framework describing the fiscal balance and debt dynamics. Fan charts showing the simulated probabilistic distributions of possible trajectories of fiscal variables are used to assess potential risks. Compared to the standard IMF DSA, this analysis covers a 10-year forecast horizon (instead of 5 years), and considers a wider range of combinations of possible shocks. It also relies on a slightly modified fiscal framework which aims to reflect public debt management more accurately, including by modeling explicitly effective interest rates associated with new debt issuance.

5. Risks to debt and fiscal sustainability appear to be contained. The simulation results show that even under adverse scenarios the risks to Dutch fiscal and debt sustainability would remain contained, with a high estimated probability that debt remains below the IMF's debt sustainability risk threshold even in adverse scenarios. This is due in large part to the strength of the fiscal position prior to the pandemic. 


\section{DEBT DYNAMICS AND FISCAL POLICY BEHAVIOR}

\section{A. Debt dynamics and interest payments}

\section{The debt dynamics is modeled to reflect public debt management. Debt} sustainability analyses often rely on the following equation describing the debt dynamics:

$$
\text { Debt }_{t}=\left(1+r_{t-1}\right) \text { Debt }_{t-1}+\text { primary deficit }_{t}
$$

With $r_{t-1}$ the interest rate in period $\mathrm{t}-1$, this equation would assume that the government rolls over all its debt at the end of each time period and refinances itself at prevailing market conditions. $r$ is also often modeled as the average interest rate on past issued debt (accrual interest rate on the existing stock of debt) instead of the interest rate associated with new debt issuance (market interest rate). Although such an approach can help derive the average cost of historical government borrowings, for forecasting purpose, it has the limitation of not linking explicitly the current market conditions to the future debt dynamics. Another limitation of equation 1 is that it does not capture the fact that at the end of each time period, only some portion of the existing stock of debt matures and is repaid. These two aspects of public debt management are important inputs for debt sustainability analyses, especially to capture the sensitivity of debt dynamics to changes in the interest rate. We develop a more detailed framework which aims to overcome those limitations.

It is assumed that at each time period, a constant fraction $(1-\gamma)$ of the existing stock of debt matures and should be repaid or refinanced. At the end of period $t$, the stock of debt is the sum of two main elements: $(i)$ the fraction of existing debt (as of end-(t-1), and including interests) which matures and must be repaid at $t$, and (ii) the primary fiscal deficit at $t$. The debt dynamics is described by the following equation (see appendix 1 for further details):

$B_{t}=\left(1+r_{t}\right) B_{t-1}+\frac{1+r_{t}-\gamma}{1-\gamma} D_{t}$

Where $B$ is the stock of debt, $r$ the interest rate on debt issuances, $D$ the primary deficit, and $t$ the time index.

\section{Interest payments are modeled to capture effective interest rates associated with}

debt issuances. In order to mimic actual debt management, interest payments should reflect the structure of debt issuances and associated specific costs. Formally, interest payments at $t$ is equal to the sum of interests on debt issued at $t-1$, plus interests on shares of past issued debt that remains to be paid. Put differently, new debt issuances will only pay interests at their respective new interest rates while past issued debt that is not yet rolled over pays interest at the rate it was originally issued. As shown in appendix 1, it is possible to derive the expression of interest payments at $t$ as a function of government gross financing needs at $t-1$ through $t-n$. By 
substituting the terms, current interest payments are derived as function of interest payments at the previous period and past issued debt and primary deficit.

$I P_{t}=\gamma I P_{t-1}+r_{t-1}\left[(1-\gamma) B_{t-2}+D_{t-1}\right]$

Where $I P$ stands for interest payments.

\section{B. Fiscal reaction function}

\section{The fiscal reaction function captures fiscal policy responses to changes in the} macroeconomic environment, given government's debt and fiscal sustainability objectives. Following the existing literature (see for example Celasun et al., 2006; and Checherita-Westphal and Zdarek, 2017) the primary fiscal deficit is estimated as a function of its own lag, the lagged level of debt, economic growth, and inflation. The reaction function is estimated over the period 1980-2018 using annual data. All coefficients are found to be statistically significant at standard minimum significance thresholds, with the expected signs (equation 4). The prediction power of the estimated reaction function broadly reflects the pattern of the Dutch fiscal policy over the past decades, with a relatively small residual (figure 1). However, the forward-looking simulation exercise will consider an alternative specification of this reaction function, including for example to model a more strongly countercyclical policy response to economic shocks.

$d_{t}^{a}=\underset{(0.09)}{0.49} d_{t-1}^{a}-\underset{(0.1)}{0.49} y_{t}^{a}-\underset{(-0.01)}{0.022} b_{t-2}^{a} \underset{(0.14)}{-0.32} p_{t}^{a}+\varepsilon_{t}^{d}$

$d, y, b$, and $p$ represent the primary deficit in percent of GDP, real GDP growth, the debt-toGDP ratio, and inflation, respectively. $a$ is an index indicating annual data. Standard errors of estimated coefficients are reported in parentheses. 
Figure 1. Prediction Power of the Fiscal Reaction Function

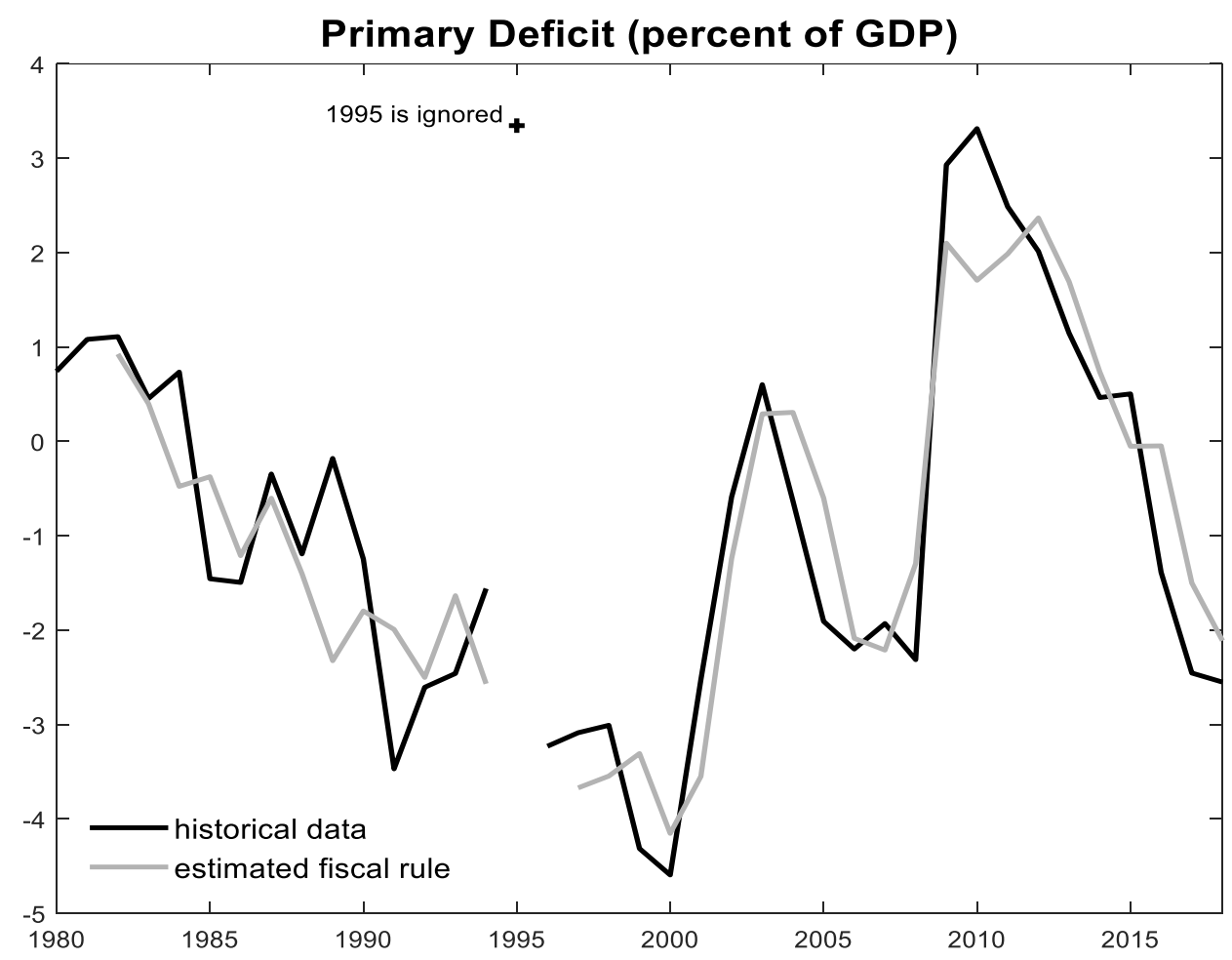

Note: 1995 is excluded due to a large government one-off transfer.

9. This framework performs well in replicating actual historical data. The accounting framework described above is used to simulate historical series of relevant fiscal and debt variables. The framework consisting of two accounting equations (equations (2) and (3)) and one behavioral equation (equation (4)) is augmented with a Kalman filter describing the variables of interest (primary deficit, debt, interest payments, and interest rate) as the sum of their respective historical observations and an error term (see the methodological appendix for further details). The system is then optimized to produce the corresponding series that ensure the accounting framework is exactly respected. The simulations assume that all debt instruments have a maturity of 5 years (implying $\gamma=0.8$ ). Appendix 2 compares the historical series and the simulated ones. The simulated series of debt dynamics and the primary balance are very close to actual data. The simulated interest rate shows some discrepancies, particularly in the first three decades of the sample. This likely captures a higher risk premium on Dutch government debt with respect to German bonds, which has narrowed down in most recent years. Historical interest payments are fairly well reproduced by the model. The good fit of our fiscal framework provides a sound basis for generating a set of projections under various scenarios. 


\section{THE MACRO (NON-FISCAL) FRAMEWORK}

\section{A. Identifying shocks to fiscal policy and public debt}

10. Fiscal policy and public debt dynamics are confronted with a set of shocks, allowing to assess their sustainability under various scenarios. Identifying such shocks requires a setup that capture co-movements among the main determinants of fiscal policy behavior and public debt. In line with previous researches, real GDP growth, inflation, and the interest rate on public debt are used as key macroeconomic variables for the purpose of this exercise. An unrestricted VAR is estimated and serves two main purposes. First, it captures the interactions between these relevant macro variables over the past three decades. Second it allows us to generate a consistent set of projections for the key determinants of debt dynamics and the fiscal balance. The estimated VAR take the form of:

$$
\left\{\begin{array}{l}
y_{t}=\underset{(0.001)}{0.003}+\underset{(0.07)}{0.7} y_{t-1}-\underset{(0.24)}{0.3} r_{t-1}-\underset{(0.18)}{0.3} p_{t-1}+\varepsilon_{t}^{y} \\
p_{t}=\underset{(0.00)}{0.00+\underbrace{1.46}_{(0.09)}} p_{t-1}-\underset{(0.09)}{0.56} p_{t-2}+\underset{(0.015)}{0.03} y_{t-1}+\varepsilon_{t}^{p} \\
r_{t}=\underset{(0.00)}{0.00+} \underset{(0.01)}{1.1} r_{t-1}-\underset{(0.12)}{0.17} r_{t-2}+\underset{(0.015)}{0.04} y_{t}+\varepsilon_{t}^{r}
\end{array}\right.
$$

Equation (5) is estimated using quarterly data over the period 1999Q1-2019Q3. Standard errors of estimated coefficients are reported in parentheses. ${ }^{3}$

\section{The shocks are modeled to capture cyclical fluctuations of the determinants of the} fiscal balance and debt dynamics. The simulation exercise further attempts to differentiate between cyclical and structural shocks. Given the 10-years forecast period under consideration, we aim at focusing on cyclical shocks, which would be more relevant for policy makers over such a medium-term horizon. We represent with $X$ the vector of variables in equation (5). The estimated parameters from equation (5) are used to relate the cyclical components of $X$ following:

$$
\tilde{\Omega}_{t}=\tilde{X}_{t}-\sum_{k=1}^{2} \hat{\delta}_{k} \tilde{X}_{t-k}-\hat{\delta}_{0}
$$

\footnotetext{
${ }^{3}$ Due to limited data availability on interest rate on Dutch government bonds, interest rate on German long-term bonds is used as a reference. The estimation is based on first difference of the logs of $y$ and $p$, while $r$ is included in the regression as a difference from a linear trend. These transformations insure stationarity of all variables. We start with a specification of equation (5) that includes two lags of each variables and then drop variables with coefficient found not to be statistically significant (only the contemporaneous values of $y$ was found to significantly explain r). Such a procedure yields a parsimonious but efficient model which captures the common dynamics of the variables.
} 
With $\tilde{X}$ the vector of deviations of the macro variables in equation (5) from their respective long-term trends estimated with a Kalman filter. $\hat{\delta}$ is the vector of parameters estimated in equation (5). $\tilde{\Omega}$ is the vector of estimated cyclical shocks which will be used in the simulation exercise as described below. ${ }^{4}$

\section{B. Simulation algorithm}

\section{Shocks to the fiscal balance and debt dynamics are stochastic and drawn from}

historical data. At each time $t+f$ of the forecast horizon, a set of three shocks corresponding the macro variables (real GDP growth, inflation, and interest rate) are drawn randomly from the pool of shocks estimated in equation (6). Precisely, at each $t+f$ of the forecast period 5000 sets of shocks are drawn and applied to the baseline forecasts (i.e. over the forecast horizon, each $x$ of the vector $X$ is defined as $x_{t+f}=\bar{x}_{t+f}+\tilde{\omega}_{x}$, where $\bar{x}$ is the trend value of $x$, and $\tilde{\omega}_{x}$ a shock estimated in equation (6)). ${ }^{5}$ This provides a wide range of possible trajectories for each of the determinants of debt and the fiscal balance. Note that by construction, such a framework takes into account the underlying correlations between the shocks, while the VAR setup provides the structure of their persistence. The macro variables are forecasted quarterly and then annualized and feed into the fiscal framework described in section B.

13. The simulated shocks imply potentially large deviations from the baseline forecasts. Appendix 3 provides a preview of possible trajectories of the macroeconomic variables under various assumptions regarding the occurrence and magnitude of the shocks, as well as histograms showing the distributions of these shocks. The magnitude of potential downturns could be larger than what was observed for example during the global financial crisis, although with a low probability. For example: there is a 5 percent probability that real GDP growth falls below -4 percent over the forecast horizon, a 5 percent probability that interest rate reaches 4 percent, and a 15 percent probability that inflation turns negative. Fiscal and debt sustainability are assessed under various "fiscal policy paths" linked to pandemic/economic "scenarios" as described below. A set of fan charts summarizing risks to fiscal balance and debt dynamics are produced for each scenario, and represent the frequency distribution of a large sample of possible paths of key fiscal and debt variables generated by mean of stochastic simulations. Each color shading represents a half-decile of the distribution of the given variable.

\section{RISKS TO DEBT AND FISCAL SUSTAINABILITY}

14. The simulations exercise uses 2022 as a starting point. As of this writing in June 2020 , most forecasts for euro area countries project a large economic contraction in 2020 followed by a significant rebound in 2021, while the economic activity is projected to return to

\footnotetext{
${ }^{4}$ Equation (6) is estimated with quarterly data over the period 1980Q1-2019Q3. This allows to increase the sample of estimated shocks.

${ }^{5}$ The shocks are drawn randomly from a pool of past observed shocks, implying that their likelihood is determined by the history. One could envisage imposing specific constraints on their occurrence, for example in a context where some macroeconomic shocks are more likely than others.
} 
"normal" growth trends from 2022 onward. The simulation exercise conducted in this paper therefore starts with the macroeconomic and fiscal conditions expected to prevail in 2022. That is, these are hopefully "post-pandemic" simulations. The focus is therefore on exploring the extent to which public debt accumulated during the pandemic can pose sustainability risks, and attempting to derive relevant implications regarding expected fiscal adjustments that may be required in the medium-term. However, it is important to note that 2020 is the starting point for the envisaged fiscal policy paths (see Figure 2) which diverge from 2021 onward; hence, the initial fiscal positions for the simulations (starting in 2022) are not identical. ${ }^{6}$

\section{The baseline forecasts are built around the April 2020 IMF WEO projections adjusted to reflect and information available as of June 2020. Additional fiscal policy} measures taken by the Dutch government to continue supporting the economic activity were announced in late-May 2020, after the publication of the April 2020 WEO. As of June 2020, forecasts from different sources (including for example the Dutch ministry of finance, the Netherlands' Central Planning Bureau, the Dutch National Bank, and OECD forecasts) project a headline fiscal deficit ranging between 6.4 and 13 percent of GDP, and a government debt at 61 to 64 percent of GDP in 2020. These projections are used as inputs for our baseline forecasts in 2020. The medium-term fiscal projections (over 2021-2025) are built around different envisaged scenarios as shown in Figure 2 (and appendix 3) and discussed in further details below. Forecasts of the macroeconomic (non-fiscal) variables are derived from the June 2020 IMF WEO Update.

16. The envisaged fiscal policy paths are assumed to be contingent on the impact of the pandemic on the economic activity. The framework developed in this paper does not model explicitly feedback loops from fiscal policy to economic activity. Rather, the objective is to assess the range of outcomes that can result from fiscal policy responses to economic shocks, to gain insight on the size of potential fiscal sustainability risks. The economic impact of the pandemic remains largely uncertain, both in terms of magnitude and persistence of the shock. This creates uncertainty regarding the size of fiscal policy measures that would be needed to contain the impact of further disruptions in economic activity, and therefore uncertainty about the initial fiscal position at the beginning of the simulation period in 2022, as discussed above. To take such uncertainties into account, three fiscal policy paths or scenarios are discussed:

- An optimistic scenario where private consumption and investment recover quickly and strongly, allowing sharp fiscal consolidation in the short-term.

- A weaker recovery scenario, with weaker-than-expected recovery of domestic demand requiring a more gradual phase out of fiscal support for the domestic economy.

\footnotetext{
${ }^{6}$ The initial fiscal position would depend on the size fiscal policy interventions in response to the magnitude and/or persistent of the economic impact of the pandemic.
} 
- A pessimistic recovery scenario where the impact of the pandemic is more persistent, and prolonged fiscal policy measures are needed to aid domestic demand.

These three fiscal policy variants should be understood in this exercise as policy responses of different intensity that would be needed to maintain similar levels of economic activity over the medium-term in the face of different underlying (pre-policy) conditions.

17. Our simulation exercise therefore models two layers of uncertainty. The first layer has to do with the evolution of the pandemic and the economy as it exits the present crisis. This layer will be modeled by constructing the three "scenarios" described above, each with its own baseline path for key fiscal variables. Each scenario corresponds to a different degree of underlying (before policy) weakness in the economy, which calls for a corresponding degree of fiscal policy support meant to result in a given rate of economic activity after the policies. The purpose of this first layer is to capture a range of possible outcomes of the pandemic for the public finances. A second layer of uncertainty is then added within each of these scenarios. This second layer of uncertainty reflects the possible series of macroeconomic shocks the economy could face during the decade following the pandemic. In this second layer, successive positive and negative shocks can push fiscal variables away from the baseline values for any given scenario. For this second layer, thousands of random simulations are performed, using shocks drawn from the historical experience of the Netherlands prior to the pandemic, as was explained in section III.B.

\section{Figure 2. Medium-term fiscal forecasts under alternative scenarios}

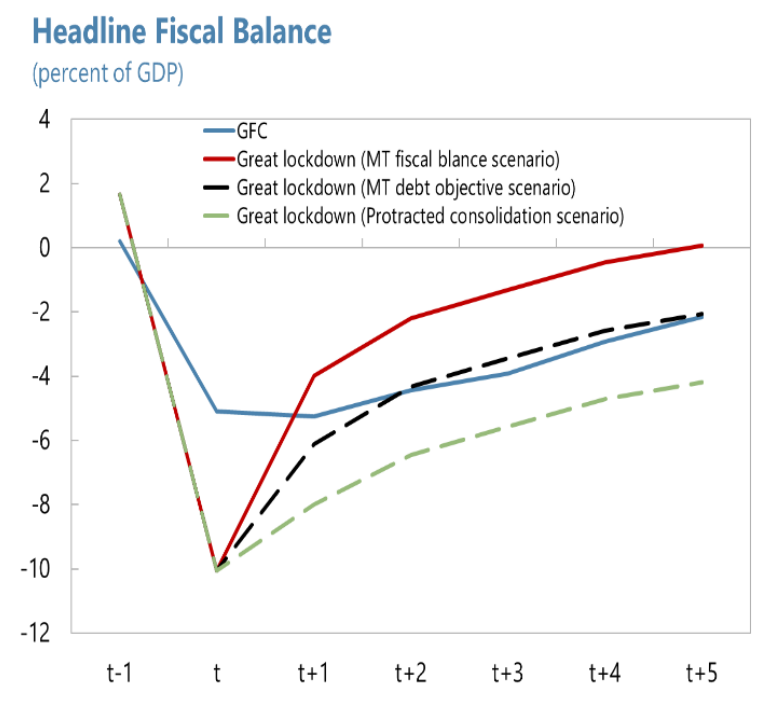

Sources: CBS and IMF staff estimates

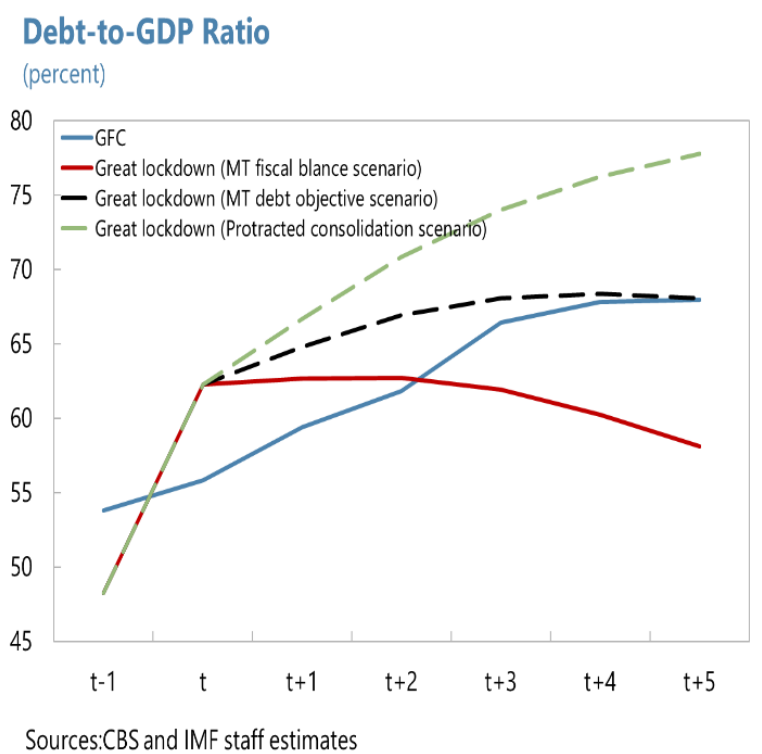

Sources:CBS and IMF staff estimates

Note: $\mathrm{t}=2009$ for the global financial crisis, and 2020 for the great lockdown. 


\section{A. A medium-term budget balance target scenario}

18. This scenario projects a front-loaded fiscal adjustment by 2025 , mainly resulting from favorable-than-expected medium-term economic developments. It is assumed that the economic impact of the COVID-19 outbreak is short-lived, with the economic activity recovering strongly by the end of 2020 followed by a sharp rebound in 2021 . In this scenario, it is assumed that government expenditure to support domestic demand during the crisis will be quickly phased out, as it is not needed. Tax deferral measures (which account for a significant share of total above-the-line fiscal package) aiming to provide tax relief to the most affected businesses, are lifted earlier than anticipated. 2020 revenue shortfalls due to tax deferrals are assumed to be mostly recovered in 2021 as a result of the economic rebound. These assumptions imply a large improvement of the fiscal balance in 2021, and a subsequent trend adjustment leading to a balanced budget in 2025. Under this scenario, the debt-to-GDP ratio falls slightly below the 60 percent limit of the European fiscal rules under the Stability and Growth Pact (SGP), over five years.

\section{A medium-term balanced budget scenario implies significantly low risks to fiscal} and debt sustainability. As indicated earlier, we now subject this path to hundreds of random drawings of the shocks estimated with equation (6), so that we can draw a fan chart of possible outcomes around this optimistic policy scenario. Under this scenario, the baseline fiscal balance remains above the 3 percent deficit limit (one of the benchmarks of the European fiscal rules under the Stability and Growth Pact, SGP) in the overwhelming majority of the simulations, with only a 5 percent (or below) probability to breach this threshold over the forecast horizon (Figure 3). The baseline debt-to-GDP ratio declines gradually, falling below 50 percent by 2030 (a debt level similar to what prevailed in 2019, before the great lockdown). Applying a wide range of macroeconomic shocks as discussed above, the simulations show that although in the short term there is a high probability that government debt will exceed the SPG's 60 percent of GDP limit, that probability falls to about 10 percent by the end of the forecast horizon.

Furthermore, the probability that the debt-to-GDP ratio exceeds 70 percent is very low (below 5 percent), suggesting low risks to debt sustainability. 
Figure 3. A medium-term budget balance scenario
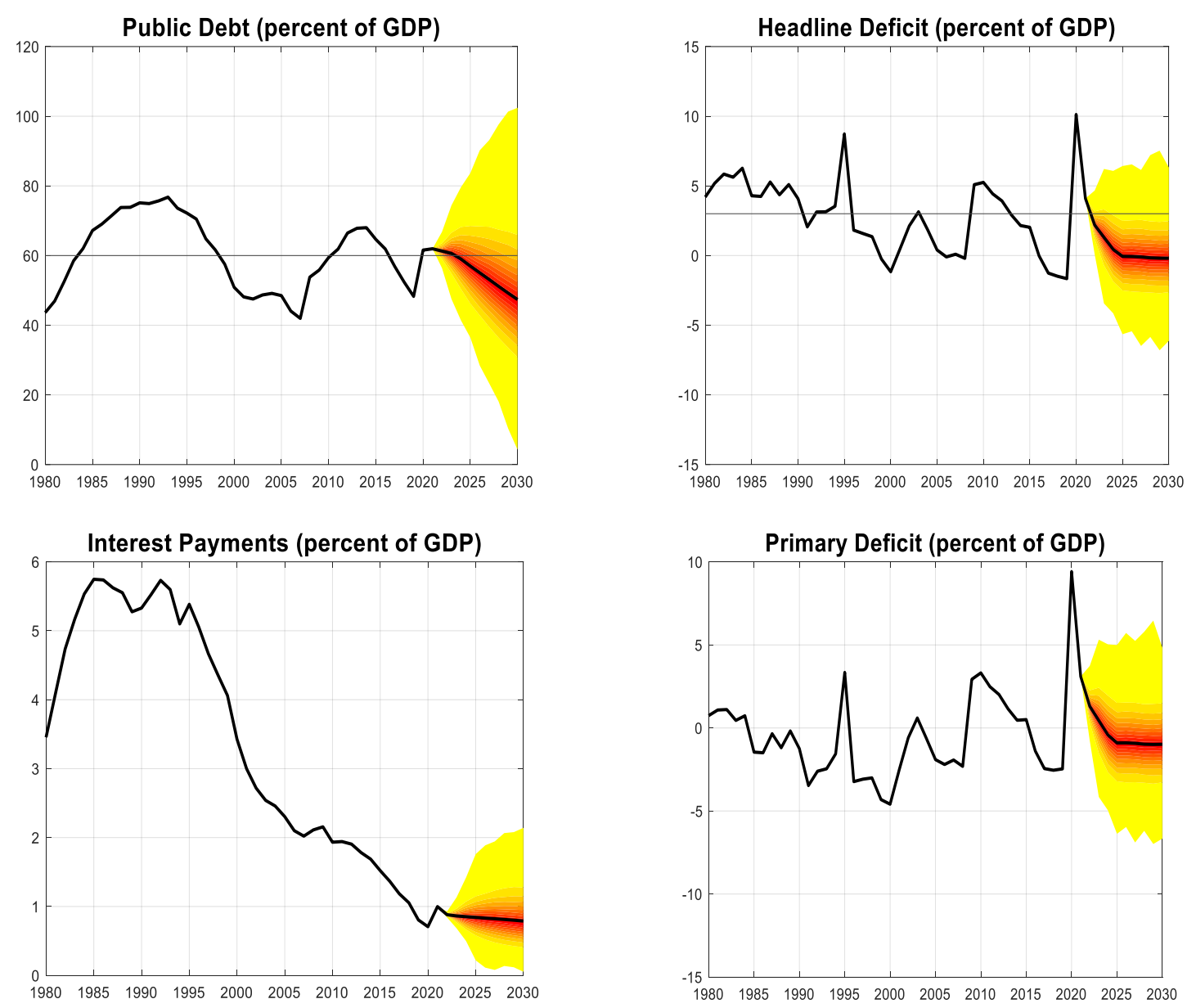

Note: each shade of color represents a 5 percent probability

\section{B. A medium-term debt objective scenario}

20. This scenario sets a medium-term debt objective in the five years following the current crisis. Based on the global financial crisis experience, the scenario projects a fiscal consolidation path that aims to achieve a debt-to-GDP ratio of about 68 percent in 2025 . This is the peak debt-to-GDP ratio that prevailed in 2014, five years after the global financial crisis (Figure 2, Appendix 3). From that level, government debt declined progressively until it fell below 50 percent of GDP in 2019. The 68 percent debt-to-GDP ratio "objective" for 2025 in this scenario is guided by the idea that from that level, public debt could be stabilized, or could be gradually reduced, as was the case after 2014. The choice of an objective of debt stabilization for the exercise in this section is motivated by the interest in exploring sustainability risks 
surrounding such a policy choice, which would be different from the debt reduction objectives that animated policy choices following the GFC.

\section{Under such a debt objective scenario, risks to fiscal and debt sustainability remain}

largely contained. Figure 4 provides fan charts for the main fiscal variables under this scenario. The stochastic simulations suggest that there is a high probability that the headline fiscal balance remains below the 3 percent of GDP deficit threshold in the short term, reflecting still high fiscal deficits in the baseline. However, as further adjustment takes place over the medium-term, the risk to breach the 3 percent of GDP fiscal deficit limit declines markedly, although it remains significant, with a probability of about 25 percent over 2025-2030. The debt level remains stable in the baseline over the forecast horizon, and in fact there is a 15 to 35 percent probability that government debt will fall below the SGP's limit of 60 percent of GDP by 2030. Nevertheless, at the other tail of the distribution, the debt-to-GDP ratio will exceed the average pre-pandemic (2019) debt-to-GDP ratio in the Euro Area, of 84 percent with only a 5-10 percent probability by 2030 , suggesting low risks to debt. ${ }^{7}$

Figure 4. A medium-term debt objective scenario
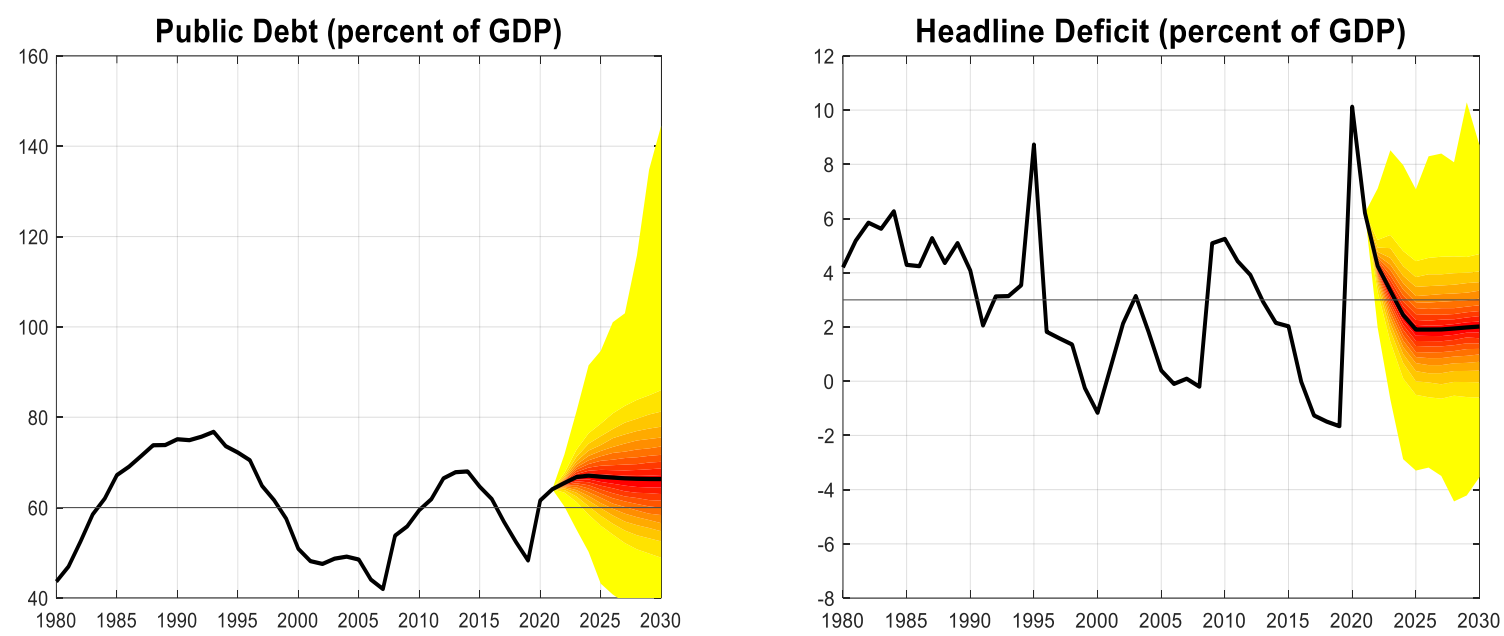

\footnotetext{
${ }^{7}$ See the IMF April 2020 Fiscal Monitor.
} 

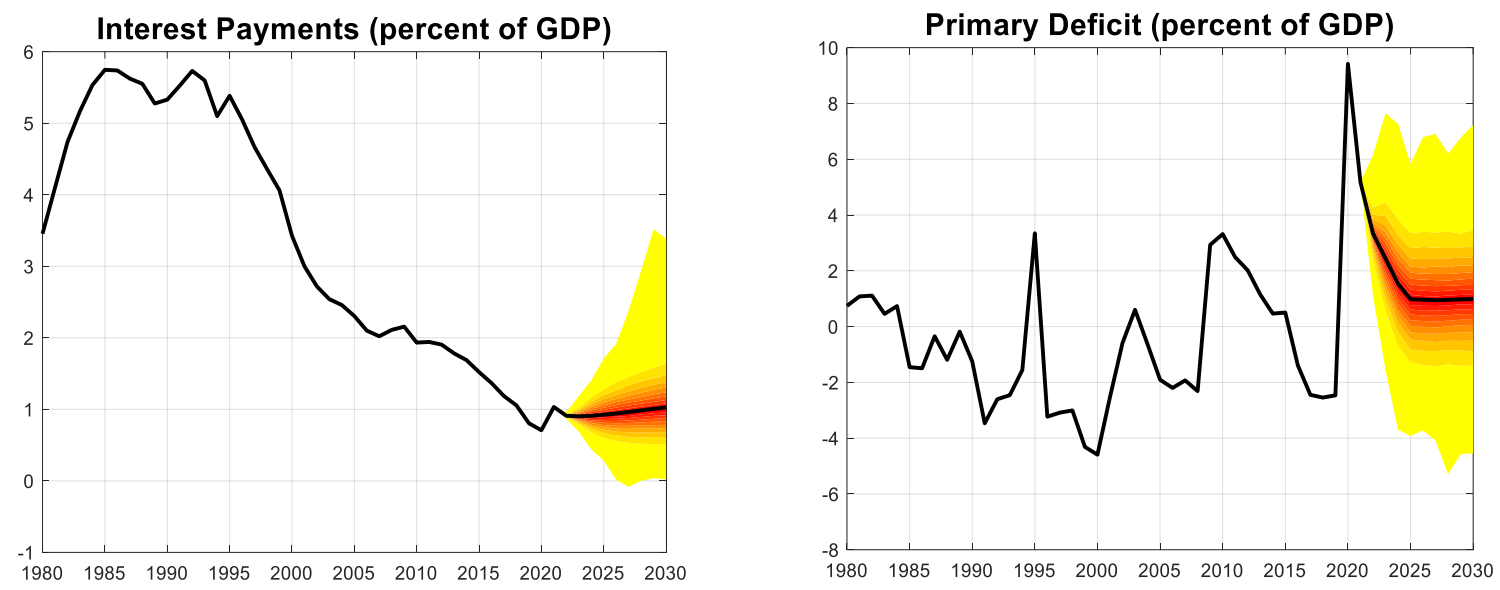

Note: each shade of color represents a 5 percent probability

\section{A protracted fiscal consolidation scenario}

22. This scenario assumes a more gradual (protracted) fiscal consolidation trajectory (without specifying a debt target) over the medium term. It may be argued that the consolidation path discussed in the previous scenarios are too optimistic or too conservative. After all, the impact of the great lockdown has so far had a much larger impact on the economic activity compared to the global financial crisis. The fiscal deficit in 2020 is projected on average to be almost twice as large as the one prevailing in 2009, and the change in government debt-toGDP ratio comparatively larger. As discussed earlier, a more protracted fiscal adjustment path may be warranted to provide further support to the economy if the impact of the COVID-19 outbreak persists after 2021 and the recovery from 2022 onwards continues to demand government support. The fiscal consolidation path in this scenario is also guided by the GFC experience. Instead of setting a medium-term debt target, as we did in the previous scenario, the consolidation path in this scenario is calibrated to be similar (or close) to the trend adjustment in the fiscal deficit observed after the GFC.

\section{A more protracted fiscal consolidation path implies higher fiscal deficits and a} continuing, gradual increase in the level of debt over the medium term (Figure 5). Under this scenario, the baseline fiscal deficit in percent of GDP most likely remains above the 3 percent limit by the end of the forecast horizon. There is approximately a 25 percent probability that fiscal deficit falls below that threshold between 2025-2030, a probability that is significantly lower over 2022-2025. There is a significant probability, also, that debt ratios could reach levels that are markedly above what the Dutch economy is used to seeing. The baseline debt-to-GDP ratio increases to around 85 percent by 2030, with only a probability below 5 percent that it falls below 60 percent over the forecast horizon. Despite the continuous increase in indebtedness compared to the previous scenarios, the simulations suggest that even with very large macroeconomic shocks, risks to debt sustainability would remain manageable. The probability of exceeding the symbolic threshold of 100 percent of GDP is 10 percent by 2030. That is, even in this adverse scenario, in 90 percent of the simulations Dutch debt ratios 
remained below those observed in 2019 in countries such as France or Belgium (99 and 98.5 percent, respectively) and well below the average for G20 advanced economies in 2019 (113 percent). ${ }^{8}$

Figure 5. A more protracted fiscal consolidation scenario
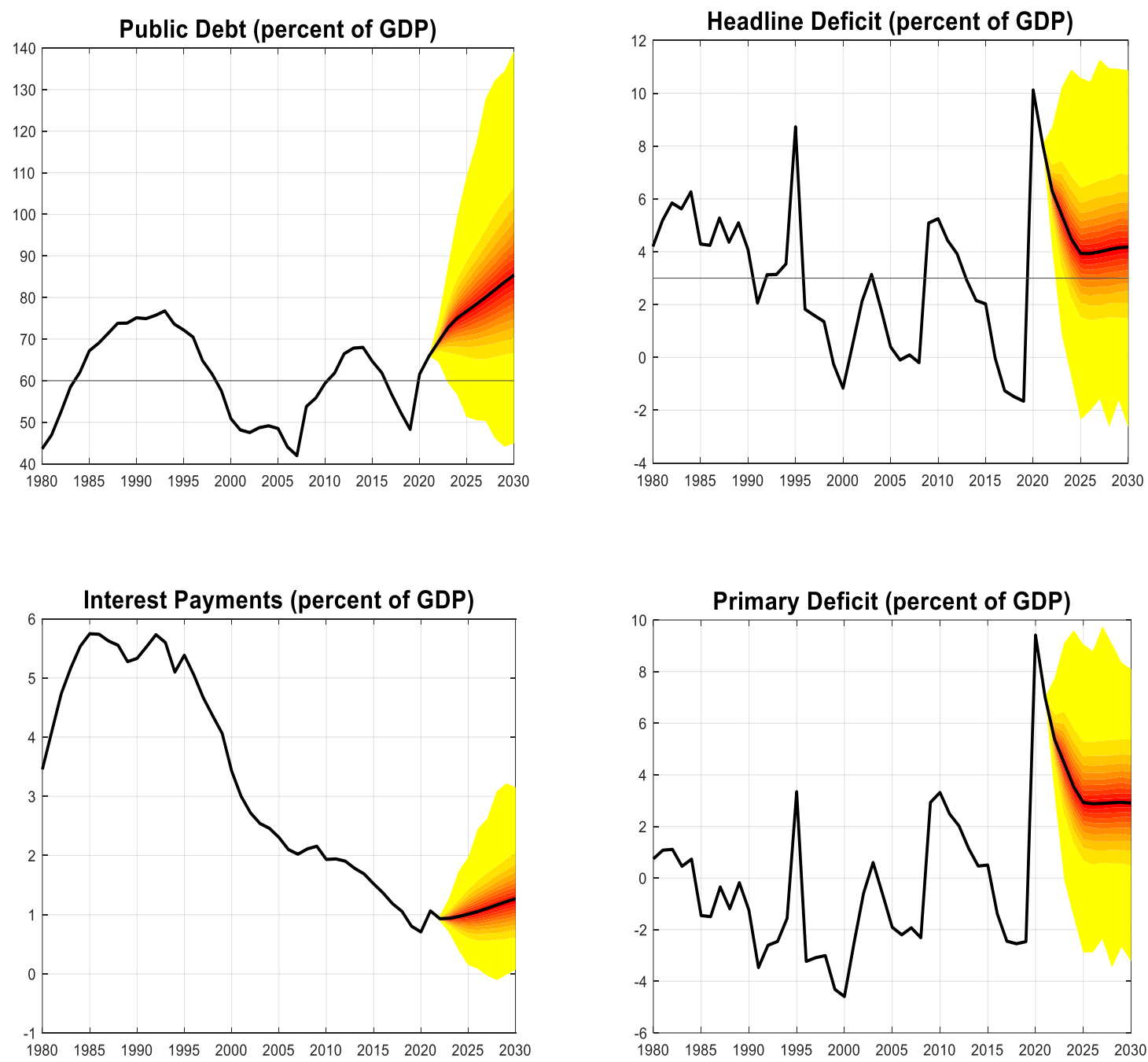

Note: each shade of color represents a 5 percent probability

\footnotetext{
${ }^{8}$ See the IMF April 2020 Fiscal Monitor.
} 


\section{Conclusion}

\section{Risks to Dutch fiscal and debt sustainability remain low, including in the post-} covid-19 era and under severe stress scenarios. The simulation exercise conducted in this paper shows that even under a significant downturn scenario and assuming an initially less favorable fiscal position due to the persistent economic impact of the outbreak, risks to the Dutch fiscal and debt sustainability remain contained. Figure 6 summarizes some key findings by providing the probability that public debt and fiscal deficits exceed certain thresholds at some point in the forecast horizon, based on the full set of simulations and under all three envisaged scenarios. ${ }^{9}$ What these charts show is that although there is a significant probability that deficits may not fall below 3 percent in some of these scenarios, debt-to-GDP ratios stay below important benchmark levels, such as the pre-pandemic average ratio of debt to GDP in the euro area ( 84 percent) or in the advanced G20 countries (113 percent) in a large majority of the simulations (i.e., with "very high probability"). That is, the large buffers with which the Netherlands came into the pandemic allow it to appear resilient to a large majority of the macroeconomic shocks and risk scenarios considered in this paper. Considering the current context where escape clauses are activated and the 3 percent of GDP deficit and 60 percent debt-to-GDP ratio limits are not binding, one could use past crises as a reference for assessing risks. Figure 6 suggests that the probability of exceeding a debt level of around 70 percent of GDP (similar to the peak debt-to-GDP ratio after the GFC and the European debt crisis) at least once in the next ten years is below 10 percent under the budget balance scenario, and around 55 percent under the debt objective scenario. The probability that the fiscal deficit falls below 5 percent of GDP (the largest deficit observed during the GFC and European debt crisis) is around 1 percent under the budget balance scenario, and 5 percent under the debt objective scenario. Although risks of larger debt and fiscal deficits are higher under the protracted consolidation scenario, these levels remain fairly low when compared to other European advanced economies in the aftermath of the great lockdown. In the midst of the ongoing crisis, this also suggests that fiscal policy can continue to provide support to economic activity if needed, without involving exceedingly adverse tradeoffs in terms of the risks such additional fiscal support may imply for medium-tern fiscal sustainability. ${ }^{10}$

\footnotetext{
${ }^{9}$ This is different from the fan charts which show the distribution of probabilities at each point in time.

${ }^{10}$ Sustainability, moreover, is also supported by ECB's monetary policy stance, including the various asset purchasing programs, and the recovery package recently agreed by EU member states. Both contribute to ease European governments' financing constraints, including by significantly reducing the costs of financing.
} 
Figure 6. Probability distributions of debt and fiscal deficit over the forecast horizon
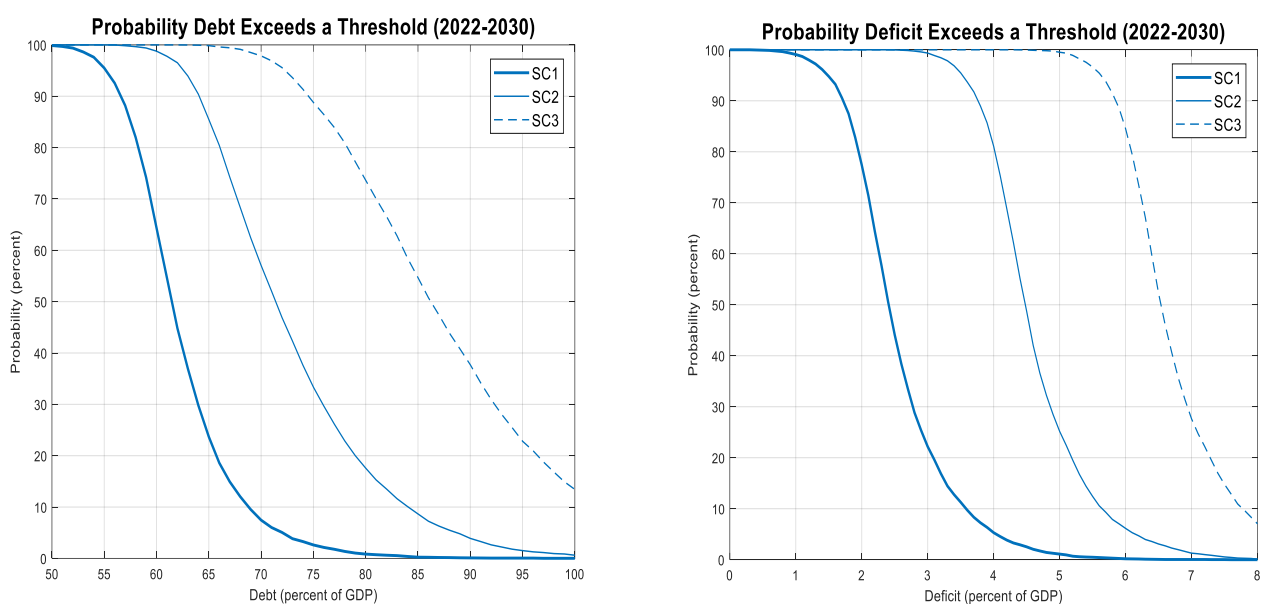

SC1: medium-term budget balance scenario; SC2: medium-term debt objective scenario; SC3: protracted consolidation scenario.

\section{The medium-term policy implications of this sustainability analysis are also}

timely. Should the impact of the covid-19 outbreak be short-lived as currently assumed, Dutch fiscal policy objectives would continue to be focusing on medium-to-long-term targets. Maintaining a strong fiscal position would help strengthen resilience to future shocks. In that regard, the SGP deficit and debt limits would seem to remain useful benchmarks for fiscal policy over the medium-term. With the next general elections to be held in 2021, the authorities have initiated the process to evaluate the current fiscal framework and define budgetary objectives for the incoming government legislature, covering the period 20212025. In a context of possibly subdued potential output, fiscal policy can play a vital role to support growth potential and ensure sustained long-term growth. The CPB 2019 Aging Report provides a long-term (over a 60-year horizon) assessment of Dutch fiscal sustainability. The report suggests that under current policies, public services cannot be sustained in the long-term, including due to unfavorable demographic developments and lower potential growth. ${ }^{11}$ Although the 10-year horizon covered in our simulation exercise does not have such a long-term perspective, it shows that space would remain available over at least two successive legislatures, allowing fiscal policy to continue supporting structural investment in the medium-term. Moderate fiscal deficits, as opposed to a return to the fiscal surpluses of the recent past, would not jeopardize long-term fiscal sustainability (as discussed above, a policy consistent with a trend deficit slightly above the SGP's MTO over the medium term would not create significant risks to debt sustainability). This would be especially true if fiscal deficits reflect support to long-term economic growth, and if the real GDP growth rate exceeds the real cost of additional government debt. For example, targeted measures to enhance productivity growth would boost potential output growth and contribute to ensure fiscal sustainability in the long run.

\footnotetext{
${ }^{11}$ The CPB model also assumes constant social spending arrangements and takes into account the impact of some longer-term developments such as demographic on social security and health care expenditure.
} 


\section{APPENDICES}

\section{Appendix 1. Methodology}

In what follows, $B$, the stock of public debt includes amortizations and interest payments. It is assumed that at each time period, and fraction $(1-\gamma)$ of that stock of debt (including interest payments) has to be repaid.

\begin{tabular}{lc} 
Variable description: & Symbol \\
\hline Nominal public debt, end of period & $B$ \\
Nominal primary deficit & $D$ \\
Nominal interest payments & $I P$ \\
Gross financing needs & $F$ \\
New debt issuance & $N$ \\
Interest factor (i.e. $1+r$, with $r$ the interest rate) & $R$ \\
Share of past debt that does not have to be rolled-over & $\gamma$ \\
\hline
\end{tabular}

\section{Debt dynamics}

At each time period $(t)$, it is assumed that a proportion $(1-\gamma)$ of the existing stock of debt is rolled-over. Government gross financing needs at $t$ can therefore be modeled as:

$F_{t}=(1-\gamma) B_{t-1}+D_{t}$

A new debt is then issued to cover the financing needs. The total amount of the newly issued debt $N_{t}$, (i.e. including the future interest payments) is given by:

$N_{t}=\frac{F_{t}}{H_{t}} \quad \Leftrightarrow \quad N_{t} H_{t}=F_{t}$

Where $H_{t}$ is the bonds' price. The bonds' price is further related to the annualized accrual interest factor $R$ following:

$R_{t}=\frac{\gamma H_{t}+(1-\gamma)}{H_{t}} \quad \Leftrightarrow \quad H_{t}=\frac{1-\gamma}{R_{t}-\gamma}$

The stock of debt at $t$ is therefore the sum of: (i) the share of debt at ( $t-1)$ that has not yet matured, $\gamma B_{t-1}$, and (ii) new debt issuance, $N_{t}$.

$B_{t}=\gamma B_{t-1}+N_{t}$

From (1), (2), (3) and (4), the debt dynamics is given by: 
$B_{t}=R_{t} B_{t-1}+\frac{R_{t}-\gamma}{1-\gamma} D_{t} \quad \Leftrightarrow \quad B_{t}=\left(1+r_{t}\right) B_{t-1}+\frac{1-\gamma+r_{t}}{1-\gamma} D_{t}$

\section{Interest payments}

Following the description of the debt dynamics discussed above, accrual interest payments at $t$ should be equal to the sum of interest payments on debt issued at $t-1$, i.e. $\left(r_{t-1}-1\right) F_{t-1}$, plus interest payments on all past issued debts that remain to be paid:

$I P_{t}=r_{t-1} F_{t-1}+\left[r_{t-2} \gamma F_{t-2}+r_{t-3} \gamma^{2} F_{t-3}+\cdots+r_{t-n} \gamma^{n-1} F_{t-n}+\cdots\right]$

The term in brackets in equation (6) represents the interest payments on proportions of debt issued at $(t-2) \ldots(t-n)$ that are still due at the current period.

Using (1) and noticing that the expression in bracket equal $\gamma I P_{t-1}$, equation (6) can take the form of:

$I P_{t}=\left(R_{t-1}-1\right)\left[(1-\gamma) B_{t-2}+D_{t-1}\right]+\gamma I P_{t-1} \Leftrightarrow I P_{t}=r_{t-1}\left[(1-\gamma) B_{t-2}+D_{t-1}\right]+\gamma I P_{t-1}$

\section{Bond price}

Equation (5) describing the accrual interest rate is derived from the expression of the bond price as described below.

Consider a unit price bond, i.e. a bond with a value of 1 . Assuming a portion $(1-\gamma)$ of the bond is repaid at the end of each period (e.g. in the form of coupon), the respective successive payments would be:

$$
(1-\gamma), \underbrace{(1-\gamma) \gamma}_{t_{1}}, \underbrace{(1-\gamma) \gamma^{2}}_{t_{3}}, \ldots \underbrace{(1-\gamma) \gamma^{n-1}}_{t_{n}}, \ldots
$$

The nominal value of the bond (i.e. the nominal unit price) corresponds to the sum of discounted values of the payments.

$$
H_{t}=\sum_{k=1}^{n} \frac{(1-\gamma) \gamma^{k-1}}{R_{t}^{k}}=(1-\gamma) \sum_{k=1}^{n} \frac{\gamma^{k-1}}{R_{t}^{k}}
$$

With $R$ the interest factor, e.g. $R=(1+r)$.

For sufficiently large $n,(2)$ can simplified as: 


$$
H_{t}=(1-\gamma) \frac{\frac{1}{R}-0}{1-\frac{\gamma}{R}}=\frac{1-\gamma}{R-\gamma}
$$

\section{Simulations of historical data}

Equations 2, 3 and 4 in the main text are augmented with a Kalman filter described as follow:

$$
\left\{\begin{array}{l}
D=D_{o b s}+\varepsilon\left(D_{o b s}\right) \\
B=B_{o b s}+\varepsilon\left(B_{o b s}\right) \\
I P=I P_{o b s}+\varepsilon\left(I P_{o b s}\right) \\
r_{-} N L D=r_{-} D E U_{o b s}+R P \\
R P_{t}=R P_{t-1}+\varepsilon(R P)
\end{array}\right.
$$

Where "obs" stands for "observed" (actual data), $\varepsilon(\mathrm{X})$ is the error term associated with $\mathrm{X}, R P$ is a risk premium. As discussed in the main text, due to limited data availability on interest rates (r) on Dutch long-term bonds, we use yields on German (DEU) government bonds as reference to generate the corresponding series for the Netherlands (NLD). The later is modeled as DEU long-term interest rate plus a risk premium $(R P)$.

The system consisting of equations 2, 3, 4, and the Kalman filter is optimized so that the two accounting equations ( 2 and 3 ) hold, while minimizing the error terms $\varepsilon(X)$. This allows us to simulate corresponding series of key fiscal variables of interest (appendix figure 2) 
Appendix 2. Simulated series based on the fiscal framework described in section B.
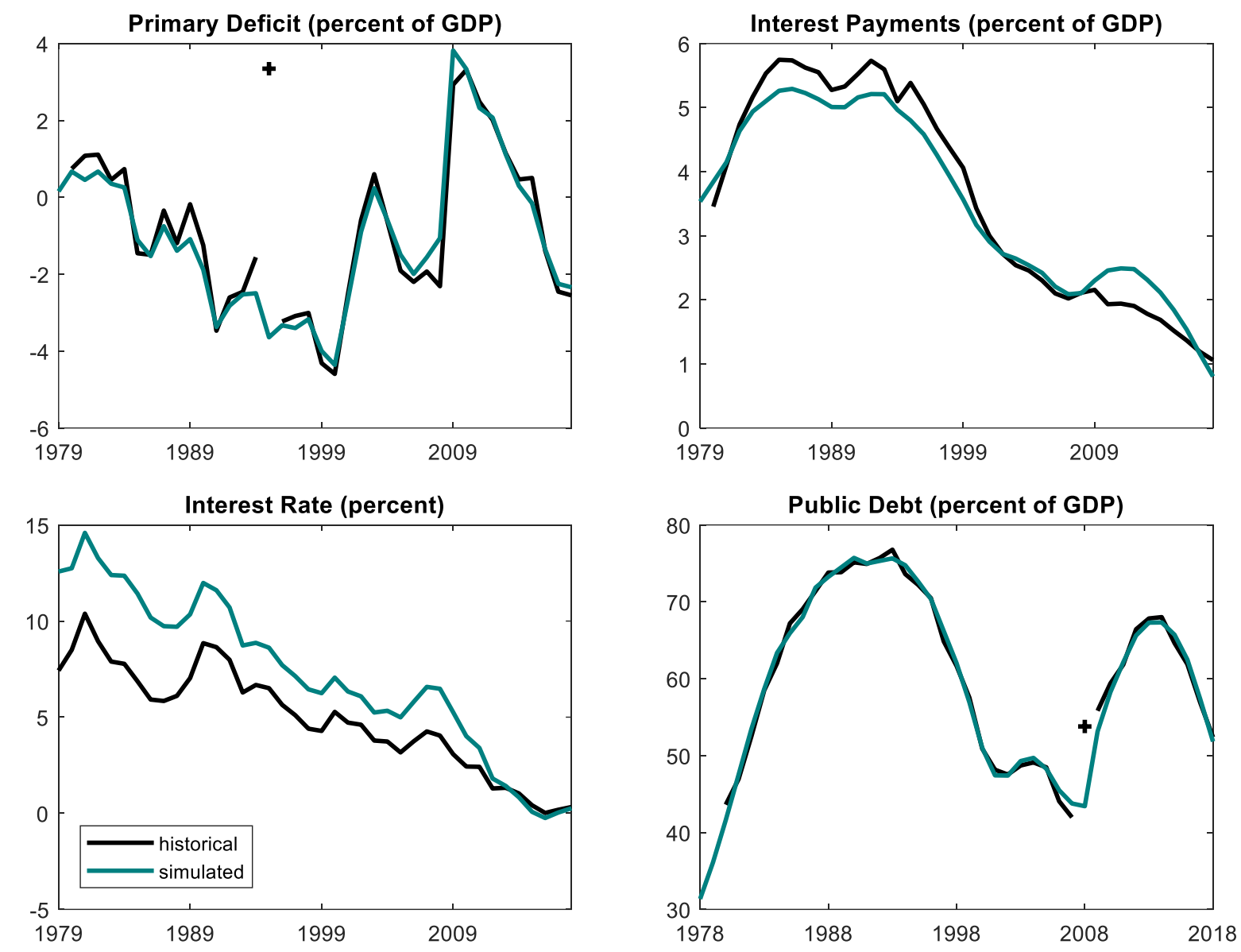


\section{Appendix 3. Medium-term forecasts under alternative scenarios}

\begin{tabular}{lrrrrrrr} 
Gobal financial crisis & 2008 & 2009 & 2010 & 2011 & 2012 & 2013 & 2014 \\
\hline Real GDP growth & 2.2 & -3.7 & 1.3 & 1.5 & -1.0 & -0.1 & 1.4 \\
Inflation & 2.2 & 1.0 & 0.9 & 2.5 & 2.8 & 2.6 & 0.3 \\
Headline fiscal balance (\% GDP) & 0.2 & -5.1 & -5.2 & -4.4 & -3.9 & -2.9 & -2.2 \\
Debt-to-GDP ratio & 53.8 & 55.8 & 59.4 & 61.8 & 66.4 & 67.8 & 68.0 \\
\hline & & & & & & & \\
& & & & & & & \\
Great lockdown & 2019 & 2020 & 2021 & 2022 & 2023 & 2024 & 2025 \\
\hline Real GDP growth & 1.8 & -7.7 & 5.0 & 2.0 & 1.7 & 1.5 & 1.5 \\
Inflation & 2.7 & 0.5 & 1.2 & 1.4 & 1.8 & 1.9 & 2.0 \\
& & & & & & & \\
MT fiscal blance scenario & 1.7 & -10.1 & -4.0 & -2.2 & -1.3 & -0.5 & 0.1 \\
Headline fiscal balance (\% GDP) & 48.3 & 62.3 & 62.7 & 62.7 & 61.9 & 60.3 & 58.1 \\
Debt-to-GDP ratio & & & & & & & \\
MT debt objective scenario & 1.7 & -10.1 & -6.1 & -4.3 & -3.4 & -2.6 & -2.1 \\
Headline fiscal balance (\% GDP) & 48.3 & 62.3 & 64.8 & 66.9 & 68.1 & 68.4 & 68.1 \\
Debt-to-GDP ratio & & & & & & & \\
Protracted consolidation scenario & 1.7 & -10.1 & -8.0 & -6.4 & -5.6 & -4.7 & -4.2 \\
Headline fiscal balance (\% GDP) & 48.3 & 62.3 & 66.7 & 70.9 & 74.0 & 76.2 & 77.8 \\
Debt-to-GDP ratio & & & & & &
\end{tabular}


Appendix 4. Shock Simulations and Frequency Distributions
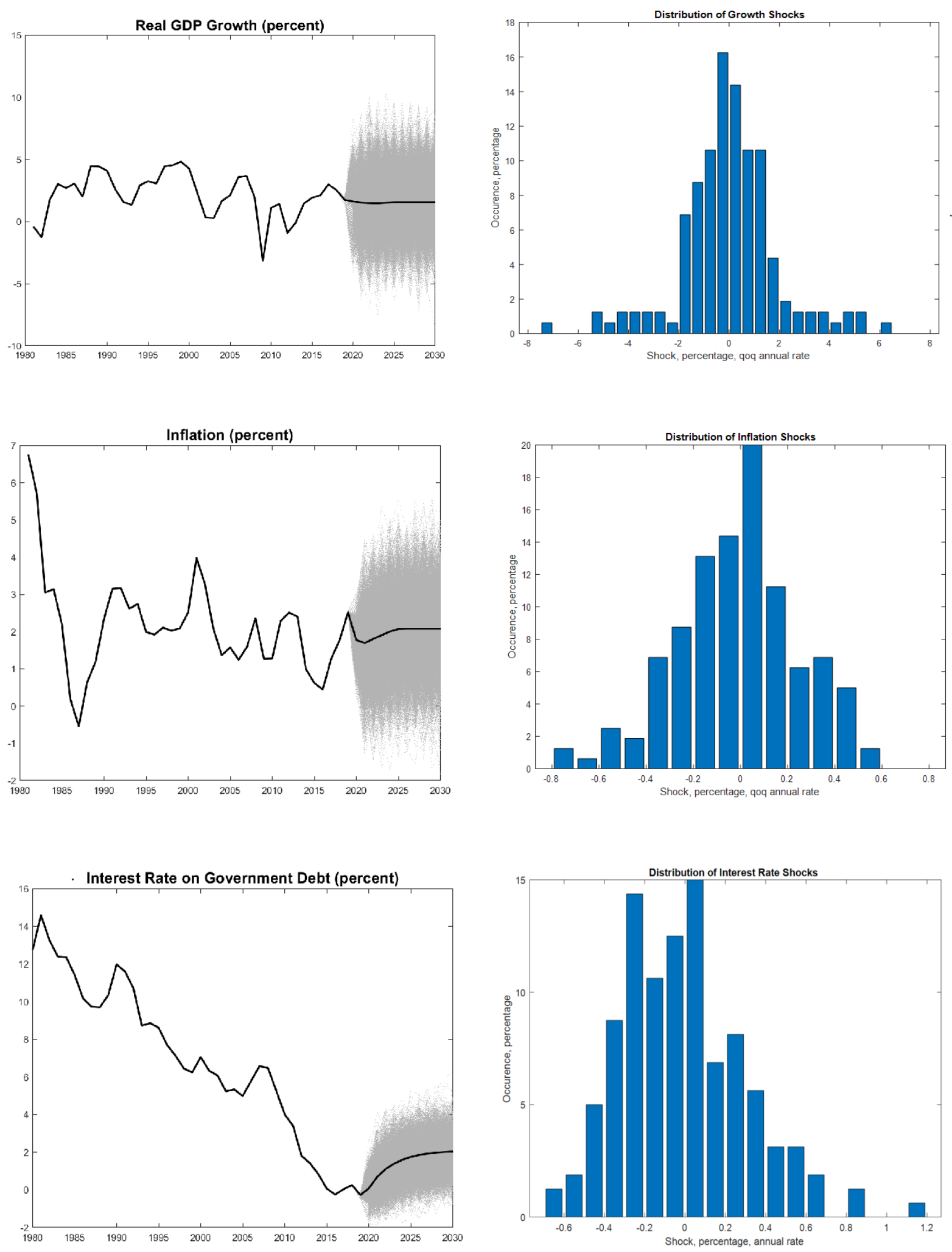

(CInternational Monetary Fund. Not for Redistribution 


\section{REFERENCES}

Celasun, O., Debrun, X., Ostry, J.D., (2006), Primary surplus behavior and risks to fiscal sustainability in emerging market countries: a "fan-chart" approach. IMF Working Paper $06 / 67$.

Checherita-Westphal, C., and Zdarek, V. (2017), Fiscal reaction function and fiscal fatigue: evidence for the euro area. ECB Working Paper Series, No 2036/March 2017.

CPB 2019 Aging Report (“Zorgen om morgen"). CPB, December 2019: https://www.cpb.nl/zorgen-om-morgen

IMF April 2020 Fiscal Monitor, "Policies to support people during the COVID-19 pandemic". International Monetary Fund.

Vierke, H., and Masselink, M., 2017, The Dutch budgetary framework and the European fiscal rules. Economic Brief 027, European Commision. 